University of Nebraska - Lincoln

DigitalCommons@University of Nebraska - Lincoln

Sociology Department, Faculty Publications

Sociology, Department of

2010

\title{
Pregnancy Intentions Among Women Who Do Not Try: Focusing On Women Who Are Okay Either Way
}

Julia McQuillan

University of Nebraska-Lincoln, jmcquillan2@Unl.edu

Arthur L. Greil

Alfred University, fgreil@alfred.edu

Karina M. Shreffler

Oklahoma State University, karina.shreffler@okstate.edu

Follow this and additional works at: https://digitalcommons.unl.edu/sociologyfacpub

Part of the Sociology Commons

McQuillan, Julia; Greil, Arthur L.; and Shreffler, Karina M., "Pregnancy Intentions Among Women Who Do Not Try: Focusing On Women Who Are Okay Either Way" (2010). Sociology Department, Faculty Publications. 97.

https://digitalcommons.unl.edu/sociologyfacpub/97

This Article is brought to you for free and open access by the Sociology, Department of at DigitalCommons@University of Nebraska - Lincoln. It has been accepted for inclusion in Sociology Department, Faculty Publications by an authorized administrator of DigitalCommons@University of Nebraska - Lincoln. 


\title{
Pregnancy Intentions Among Women Who Do Not Try: Focusing On Women Who Are Okay Either Way
}

Julia McQuillan, Ph.D.

The University of Nebraska at Lincoln, jimcquillan2@unlnotes.unl.edu

Arthur L. Greil, Ph.D.

Alfred University, fgreil@alfred.edu

Karina M. Shreffler, Ph.D.

Oklahoma State University, karina.shreffler@okstate.edu

Corresponding author - J. McQuillan, Department of Sociology, University of Nebraska-Lincoln,

706 Oldfather Hall, Lincoln, NE 68588-0324; tel 402 472-6616, fax 402 472-6070

\begin{abstract}
Objectives: Are women who are intentional about pregnancy (trying to or trying not to get pregnant) systematically different from women who are "okay either way" about getting pregnant?

Methods. We use a currently sexually active subsample $(n=3,771)$ of the National Survey of Fertility Barriers, a random digit dialing telephone survey of reproductive-aged women (ages 25-45) in the United States. We compare women who are trying to, trying not to, or okay either way about getting pregnant on attitudes, social pressures, life course and status characteristics using bivariate analyses (chi-square tests for categorical and ANOVA tests for continuous variables). Multivariate multinomial logistic regression provides adjusted associations.

Results. Most women say that they are trying not to get pregnant (71\%) or are okay either way (23\%); few are trying to get pregnant. Among women with no prior pregnancies $(n=831)$, more say that they are trying to get pregnant $(14 \%)$ but a similar percentage are okay either way (26\%). Several characteristics distinguish those trying to from those okay: fertility intentions, importance of motherhood, age, parity, race/ethnicity and self identifying a fertility problem. Additional characteristics are associated with trying not to get pregnant compared to being okay: ideal number of children, wanting a baby, trusting conception, relationship satisfaction, race ethnicity, economic hardship, and attitudes about career success.

Conclusion. Women who are "okay either way" about pregnancy should be assessed separately from women who are intentional (trying to, trying not to) about pregnancy.
\end{abstract}

Keywords: Pregnancy intentions, pregnancy planning, life course, fertility intentions

$\mathrm{U}$ nintended or unplanned pregnancies are a major concern in the United States because of their serious consequences, including poorer child health and development, less parental relationship stability, and less well-being of the mother (1). Thinking about pregnancies as either intended or unintended, however, assumes that there are only two possible pregnancy intentions: trying to get pregnant or trying not to get pregnant. A third option is that some women may be less intentional about pregnancies. Morgan (2) first drew attention to the response "I don't know" as providing important information about women who do not have fertility intentions. We build upon previous qualitative research suggesting that some women prefer to think of themselves as "okay either way" rather than as trying to or trying not to get pregnant (3). We argue that recogniz- ing women who are "okay either way" enhances understanding of ambivalence about pregnancy. Questioning the assumption that most women are explicitly intentional about pregnancy raises interesting questions. For example, where are women who are "okay either way" about a pregnancy categorized in a scheme that presumes most pregnancies are intended or unintended/ planned or unplanned? Are they more likely to refuse to answer, say "I don't know," or to choose a category that does not quite fit their experience?

Answering these questions is more than an exercise in categorization. Accurate measures of women's pregnancy intentions are important for estimating unmet need for contraception, building more effective family planning programs, promoting infant health, and helping maternal and infant wellbeing $(4,5)$. Policies and 
public health campaigns that assume most women are intentional in their pregnancy intentions are unlikely to be effective with women who are less intentional or more ambivalent toward pregnancy. Additionally, women who are "okay either way" and who presumably are not using contraception or are intermittently using it will likely take longer to identify a fertility problem. Among women with fertility barriers, delayed recognition of a problem increases the likelihood of fertility foregone (2), and even for women who were originally okay either way, could result in elevated distress (6).

The response "okay either way" came from preliminary in-person interviews with women who had had over a year of unprotected intercourse without conception and without seeking help for infertility (3). These interviews with seven women were designed to improve the telephone survey. When asked if they were trying to or trying not to conceive at that time, several said "I was okay either way". Therefore this response category was added to the options "trying to" and "trying not to" in the National Survey of Fertility Barriers (NSFB). Our goal is to distinguish women who say they are "okay either way" from women who say they are either trying to or trying not to become pregnant. We examine current pregnancy intent for all sexually active women in the sample as well as for the subset of women with no prior pregnancies.

\section{Dimensions of Pregnancy Intentions}

Recent investigations of pregnancy intentions generally divide pregnancies into intended/unintended or planned/unplanned (5, 7-10). Unintended pregnancies typically include pregnancies that are reported as mistimed, unwanted, or ending in induced abortion (1), whereas planned pregnancies involve intentions to become pregnant, stopping contraception, partner agreement, and desired timing (11). Demographic studies of individual fertility motivations and/or intentions describe retrospective accounts of intendedness as "pregnancy intentions" and prospective intentions are called "fertility intentions." Fertility intentions are measured by questions about how much women would like to have a baby, want a baby, or intend a baby. There are multiple dimensions of intentions, including individual, partner, and community values and attitudes as well as life course factors such as career and education goals and situations (12-18).

Although the classification of pregnancies into intended and unintended remains quite common, there is evidence that this simple dichotomy does not reflect women's lived experience $(2,3,5,11,19-23)$. Intended and unintended are best conceptualized as two ends of a continuum (13). Women who are unsure could either be transitioning between intentions $(2,24)$ or could simply be less "planful" about their fertility. Rijken's (25) interviews with couples showed that only a few had explicit discussions about having children. Rijken also found more thought about avoiding pregnancy (e.g. taking birth control) than about deliberately planning to have a child.

Women's answers to questions about the planning or wantedness of a pregnancy are often inconsistent with their expressed desires to avoid pregnancy and with their contraceptive behaviors. More than half of unplanned pregnancies occur among women who were not using any method of contraception the month they conceived (26), suggesting the existence of a category other than "trying to" or "trying not to." The incongruence between not wanting to get pregnant and inconsistent contraceptive use could reflect ambivalence towards pregnancy (27).

Numerous maternal characteristics associated with intentional and planned pregnancies should be relevant to our measure of pregnancy intent. We briefly mention the characteristics here that we include in our model. The following are associated with planning pregnancies: increased age $(6,9)$, higher educational attainment $(6,9$, $10)$, more wealth $(7,10)$, white race/ethnicity compared to all others $(10)$, marriage $(9,10)$, more stable or higher quality relationships (8), more religiosity (17), and prior births (9). Characteristics associated with intending no births include multiple children (7), stepchildren (18), and being in a cohabiting relationship (18). Building on this considerable prior research, we contribute to efforts to understand childbearing intentions by explicitly comparing women who are "okay either way" to those who are trying to or trying NOT to get pregnant.

\section{Methods}

We used a subset of the National Survey of Fertility Barriers (NSFB) telephone survey, conducted between 2004-2006 with 4,712 women aged 25 to 45 in the United States and some of their partners (28). We analyze the 3,771 women who are currently sexually active. The Random Digit Dialing based survey first screened potential participants for inclusion to secure an oversample of minority women, women with no children, and women with a biomedical fertility barrier. The data are weighted to adjust for the disproportionate probability of selection for these groups. The estimated response rate for the sample is $53.0 \%$ for the screener and $37.2 \%$ overall. This low response rate is consistent with recent declines in participation in telephone surveys (29); however extensive comparisons with the National Survey of Family Growth indicate that the sample is representative of the intended population. This research complied with established survey research ethical standards.

\section{Concepts and Measures}

The dependent variable, pregnancy intent, was measured by the question: "Currently, are you pregnant, 
trying to get pregnant, trying not to get pregnant, or are you okay either way?" Women who were pregnant at the time of the interview, did not answer the question, or gave "other" answers were excluded from this analysis.

Attitudes. Ideal number of children was measured by the question, "If you yourself could choose the exact number of children to have in your whole life, how many would you choose?" Fertility intentions are assessed by responses to the questions, "Do you intend to have a(nother) baby?" and "In your case, how sure are you that you (will/will not have a(nother) child?" values range from very sure no $(-3)$ to very sure yes $(+3)$. Respondents who said that they would like to have a baby are coded (1) and those who did not are coded (0). Importance of motherhood was constructed by averaging responses to five questions measured on Likert scales (strongly agree to strongly disagree), for example: "Having children is important to my feeling complete as a woman," and "I always thought I would be a parent." These items form a single factor that explained $64 \%$ of the variance. The Cronbach's alpha was high $(\alpha=.86)$ for the entire sample). Religiosity was measured by four questions: 1) "How often do you attend religious services?" 2) "About how often do you pray?" 3) "How close do you feel to God most of the time?" and 4) "In general, how much would you say your religious beliefs influence your daily life?" The items were normalized and averaged; they form a single factor and have a high reliability $(\alpha=.78)$.

A scale constructed by averaging responses to questions about how much women trusted that they would conceive was created by the following questions: "I thought I would get pregnant when the time was right;" "I thought if it's God's will, I would get pregnant;" "I worried that I might not be able to get pregnant, without medical treatment" (reversed). These same items were asked of women who had never been pregnant, but about the future. Valuing work success is a dummy variable measuring responses to the question, "How important is being successful in my line of work?" 1 = very important. Valuing leisure is based on the response to, "How important is having leisure to enjoy my own interests?" 1 = very important. Self identifying as a person with an infertility problem was measured by an affirmative answer to the question: "Do you think of yourself as someone who might have trouble getting pregnant?" and compared to those who answered no.

Social pressure to have children. Very important to partner was measured by responses to the question, "It is important to my partner that we have children." $1=$ strongly agree. Grandparents want a child was measured by responses to the question, "It is important to my parents that I have children." 1 = strongly agree. Most friends/family have children was measured by responses to the question, "Thinking about your friends and family, would you say all of them, most of them, some of them, few of them, or none of them have children?" 1 = all or most of friends/family have children.

Life course. Age was measured in years. Married and cohabiting are dummy variables assessed through a question about marital status and were compared to those not currently in a union. Relationship satisfaction is a scale made up of five questions: "Taking all things together, how would you describe your relationship? Would you say that it is very happy, pretty happy, or not too happy?" and "Overall, how satisfied are you with your sexual relationship? Would you say very satisfied, pretty satisfied, or not too satisfied?" "Have you ever thought your relationship might be in trouble?" "Do you feel this way now?" and "Have you and your partner discussed the possibility of ending your relationship any time in the last three years?" Employment was measured by indicator variables for employed full time (greater than 35 hours per week) and employed part time compared to those who are in school, keeping house, retired or disabled. Parity was measured by three variables $(1,2$ or $3+$ children compared to no children).

Social status. Race was assessed using standard U.S. Census questions and was measured by three indicator variables (Black, Hispanic, Asian) with white or other as the reference category. Ethnicity was measured by an indicator for Hispanic ethnicity. Participants who chose to do the interview in Spanish were compared to those who did the interview in English. Socioeconomic status was measured by Education in years and economic hardship. Economic hardship was measured by responses to three items: "During the last 12 months, how often did it happen that you ... (1) "had trouble paying the bills," 2) "did not have enough money to buy food, clothes, or other things your household needed," and 3) "did not have enough money to pay for medical care?" This is a unidimensional scale with high reliability $(\alpha=82)$.

\section{Methods of Analysis}

The same analyses were conducted on all currently sexually active women and currently sexually active women with no prior pregnancies. For each analysis, we first used chi square for categorical variables and ANOVAs with Bonferroni post hoc tests to assess the zeroorder associations between pregnancy intent and independent variables. We then used multinomial logistic regression to assess how attitudinal, life course, and demographic characteristics are associated with pregnancy intentions, controlling for other characteristics.

\section{Results}

Table 1 displays descriptive statistics by pregnancy intention. Of the women included, $6 \%$ reported that they were trying to get pregnant, $71 \%$ were trying not to get 
pregnant, and $23 \%$ were okay either way at the time of the interview. For many study variables, those who were "okay either way" occupy a middle position between those who were trying and those who were not trying to get pregnant. Not surprisingly, women who were trying to get pregnant were more likely to want a(nother) baby than those who were okay either way, or those who were trying not to get pregnant. Responses to the general fertility intentions scale were similar; scores were highest among those who wanted to get pregnant, followed by those who were okay either way and lowest among those who were trying not to become pregnant. Women who were trying to become pregnant were more likely to self-identify as infertile than those who were okay either way and those who were trying not to become pregnant. Other variables that display this same pattern in which those who were okay either way occupy the middle position between those who are trying and those who are trying not to become pregnant are being married, all levels of parity, Spanish language, and age.

For two variables, women who said that they were okay either way had the highest scores (ideal number of children and religiosity). In some ways, those who were okay either way are more like those who were try-

Table 1. Descriptive Statistics by Pregnancy Intention Status for All Currently Sexually Active Women

\begin{tabular}{|c|c|c|c|c|c|c|c|c|}
\hline & \multicolumn{2}{|c|}{$\begin{array}{l}\text { Trying to get pregnant } \\
\qquad \begin{array}{c}n=240 \\
6 \%\end{array}\end{array}$} & \multicolumn{2}{|c|}{$\begin{array}{c}\frac{2}{\text { Okay either way }} \\
n=865 \\
23 \%\end{array}$} & \multicolumn{2}{|c|}{$\begin{array}{c}\frac{3}{\text { Trying not to get }} \\
\text { pregnant } \\
n=2,666 \\
71 \%\end{array}$} & \multirow[t]{2}{*}{$P$} & \multirow[t]{2}{*}{ Post Hoc } \\
\hline & $\mathrm{M} / \%$ & SD & $\mathrm{M} / \%$ & SD & $\mathrm{M} / \%$ & SD & & \\
\hline \multicolumn{9}{|l|}{ Attitudes } \\
\hline Intend no & $4.9 \%$ & & $46.3 \%$ & & $76.0 \%$ & & & \\
\hline Don't know/unsure & $3.3 \%$ & & $17.4 \%$ & & $9.8 \%$ & & & \\
\hline Intend yes & $91.8 \%$ & & $36.3 \%$ & & $14.3 \%$ & & & \\
\hline Would like a baby & $95.4 \%$ & & $73.2 \%$ & & $34.0 \%$ & & $* * *$ & \\
\hline Importance of Motherhood & .17 & .46 & .06 & .58 & .06 & .62 & $* * *$ & 1 v. 2,3 \\
\hline Self Identifies Infertility & $64.2 \%$ & & $38.2 \%$ & & $26.5 \%$ & & $* * *$ & \\
\hline \multicolumn{9}{|l|}{ Social Pressure } \\
\hline Very Important to Partner & $42.5 \%$ & & $34.9 \%$ & & $34.3 \%$ & & * & \\
\hline Grandparents want a child & $28.3 \%$ & & $26.0 \%$ & & $27.4 \%$ & & & \\
\hline Most friends/family have kids & $76.7 \%$ & & $81.2 \%$ & & $81.7 \%$ & & & \\
\hline \multicolumn{9}{|c|}{ Life Course } \\
\hline Age & 33.20 & 5.17 & 34.60 & .83 & 35.89 & 6.02 & $* * *$ & $1 \mathrm{v} .2 \mathrm{v} .3$ \\
\hline Married & $81.2 \%$ & & $76.4 \%$ & & $72.4 \%$ & & $* *$ & \\
\hline Cohabiting & $2.9 \%$ & & $1.7 \%$ & & $1.4 \%$ & & & \\
\hline Relationship satisfaction & 2.45 & .54 & 2.47 & .51 & 2.40 & .53 & $* * *$ & $2 \mathrm{v} .3$ \\
\hline Employed Full Time & $57.1 \%$ & & $55.4 \%$ & & $56.7 \%$ & & & \\
\hline Employed Part Time & $14.2 \%$ & & $13.4 \%$ & & $14.6 \%$ & & & \\
\hline Black & $21.3 \%$ & & $18.8 \%$ & & $16.5 \%$ & & & \\
\hline Asian & $3.3 \%$ & & $3.1 \%$ & & $1.8 \%$ & & * & \\
\hline Spanish language & $5.8 \%$ & & $4.1 \%$ & & $2.2 \%$ & & $* * *$ & \\
\hline \multicolumn{9}{|l|}{ Socioeconomic Status } \\
\hline Education in Years & 14.97 & 3.39 & 14.80 & 2.86 & 14.56 & 2.85 & * & \\
\hline Economic Hardship & 1.54 & .79 & 1.49 & .69 & .01 & .74 & & \\
\hline
\end{tabular}

${ }^{*} p<.05 ;{ }^{* *} p<.01 ; * * * p<.001$

Note: Chi-square performed for categorical variables, ANOVA with Bonferroni post hoc tests for continuous variables. 
ing to get pregnant. Those who were trying and those who were okay either way had greater trust in getting pregnant than those who were trying not to get pregnant. Similar patterns emerged for relationship satisfaction, education, Hispanic race/ethnicity, and Asian race/ethnicity. In other ways, women who were okay either way are more like those who were not trying to get pregnant than those currently trying. Women trying to become pregnant were more likely to self-identify as infertile than those who were okay either way and those trying not to become pregnant. Importance of motherhood scores were significantly higher among those trying to get pregnant than they were among those okay either way and among those trying not to get pregnant. Those who were trying to get pregnant were more likely to report that having another child is very important to their partner than women in the other two groups. Those who were trying to get pregnant were less likely to self identify as white than women who were okay either way or trying not to get pregnant.

Several characteristics do not differ significantly by current pregnancy intentions. These include the proportion stating that career success is very important, that leisure is very important, that grandparents want a child, that most family or friends have children, that are cohabiting, that are employed, are black, and the level of economic hardship.

Table 2 shows the association of the independent variables with pregnancy intentions among women who have not yet had a pregnancy. The descriptive pat-

Table 2. Descriptive Statistics by Pregnancy intent for Women with No Prior Pregnancies who are Currently Sexually Active $(N=831)$

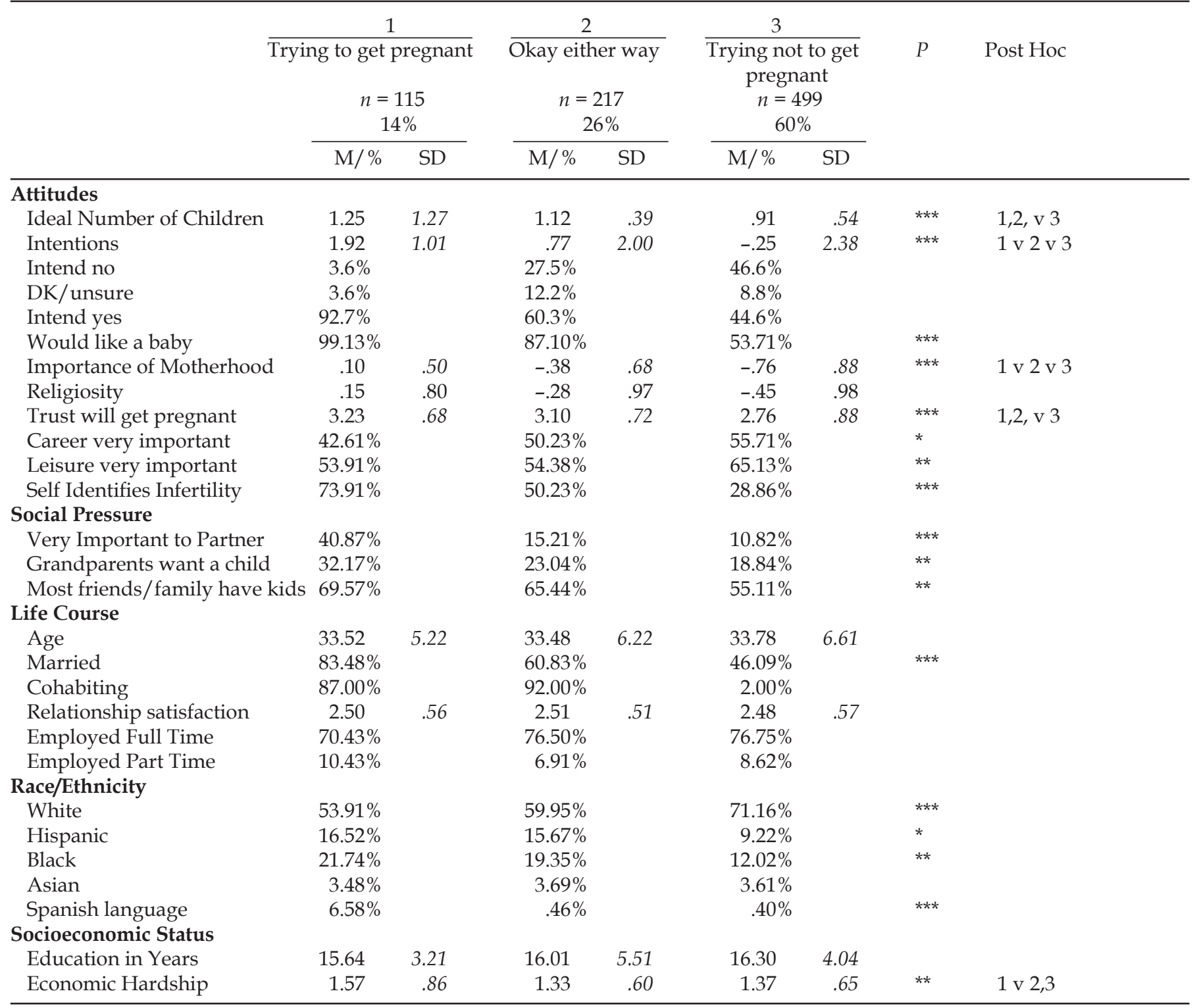

${ }^{*} p<.05 ; * * p<.01 ; * * * p<.001$

Note: Chi-square performed for categorical variables, ANOVA with Bonferroni post hoc tests for continuous variables. 
terns indicate that for most characteristics, women who were okay either way tend to fall in between those trying to and those trying not to become pregnant. Religiosity is significant and highest among the "okay either way" group when we analyze all women, but not in the subset with no prior pregnancies. Attitudes about career and leisure are significant only among women without prior pregnancies. Among the social pressure measures, the desire of parents for a grandchild and having friends and family with children are significantly different for women with no prior pregnancies. Women who say that they are trying to conceive are more likely to report that their parents want grandchildren and that they have friends and family with children. Most of the life course variables are similar in both of the analyses.
Table 3 presents the results of the two multinomial logistic regressions. The comparison of "trying" to "okay" is in the top panel and "trying not to" to "okay" in the lower panel. The analysis of women with no prior pregnancies had the larger explained variance (Nagelkerke $R^{2}=.51$ ). Several characteristics distinguish women who are okay either way from women who are trying to get pregnant. Higher fertility intentions and importance of motherhood are associated with higher odds, and higher age and parity are associated with lower odds of trying to get pregnant compared to being okay either way. Women who self identify as having a fertility problem and black women have higher odds of trying compared to being okay than women who do not self identify and white

Table 3. Multinomial logistic regression of predicting pregnancy intent (current attitude for all sexually active women (1) and for women with no prior pregnancies (2) among American women ages 25-45

(1)

Pregnancy Intention Includes all cases that are sexually active

Trying to v. Okay $n=3,771$

\section{(2)}

Pregnancy Intention Includes never pregnant

\begin{tabular}{lll}
\multicolumn{4}{c}{$n=3,771$} \\
\hline Coef. SE OR $\quad P$
\end{tabular}

\section{Attitudes}

Ideal Number of Children

Intentions

Would like a baby

Importance of Motherhood Religiosity

Trust will get pregnant

Career very important

Leisure very important

Self Identifies Infertility

Social Pressure

Very Important to Partner

Grandparents want a child

Most friends/fam have kids

Life Course

Age

Married

Cohabiting

Relationship satisfaction

Employed Full Time

Employed Part Time

Parity 1

Parity 2

Parity 3 or higher

Ethnicity and Race

Hispanic

Black

Asian

Spanish Language

Socioeconomic Status

Education in Years

Economic Hardship

Constant

$\begin{array}{rrr}.09 & .35 & 1.10 \\ .56 & .07 & 1.75 \\ .52 & .52 & 1.69 \\ .58 & .26 & 1.79 \\ -.21 & .13 & .81 \\ -.15 & .16 & .86 \\ -.15 & .21 & .86 \\ .00 & .21 & 1.00 \\ 1.23 & .21 & 3.43 \\ & & \\ .11 & .24 & 1.11 \\ -.27 & .25 & .76 \\ -.32 & .25 & .72 \\ & & \\ -.49 & .25 & .61 \\ -.73 & .85 & .48 \\ 1.87 & .95 & 6.46 \\ -.15 & .20 & .86 \\ -.38 & .24 & .68 \\ -.22 & .31 & .80 \\ -.83 & .26 & .44 \\ -.81 & .35 & .45 \\ -1.72 & .53 & .18 \\ & & \\ .50 & .29 & 1.65 \\ .98 & .30 & 2.66 \\ -.27 & .45 & .76 \\ .68 & .50 & 1.97 \\ & & \\ -.05 & .05 & .95 \\ .07 & .16 & 1.07 \\ & & \\ -.50 & 1.36 & .61 \\ & & \end{array}$

\begin{tabular}{lll}
\multicolumn{4}{c}{$n=831$} \\
\hline Coef. SE OR $\quad P$
\end{tabular}

.54

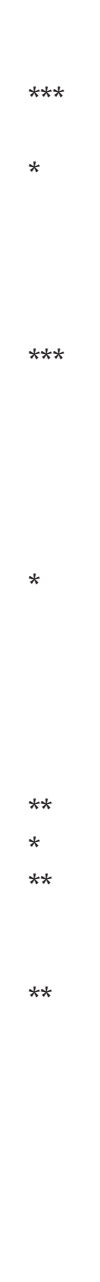

.32
-.27
1.18

*

51

.51

.12
1.09

.37

$\begin{array}{ll}-.16 & .21 \\ -.04 & .25\end{array}$

$\begin{array}{ll}-.16 & .21 \\ -.04 & .25\end{array}$

$\begin{array}{ll}-.01 & .34\end{array}$

$\begin{array}{rr}.21 & .34 \\ 1.58 & .38\end{array}$

$\begin{array}{rl}1.72 & \text { n.s } \\ 1.37 & * \\ .76 & \text { n.s } \\ 3.25 & * * \\ .85 & \\ .96 & \\ .99 & \\ 1.23 & \\ 4.87 & * * *\end{array}$

$\begin{array}{lll}.18 & .37 & 1.20\end{array}$

$\begin{array}{rrr}-19 & 38 & 82\end{array}$

$\begin{array}{lll}-.19 & .38 & .82 \\ -.41 & .36 & .67\end{array}$

$\begin{array}{lll}-.17 & .31 & .84\end{array}$

$\begin{array}{lll}.76 & 1.18 & 2.14\end{array}$

$\begin{array}{lll}1.79 & 1.39 & 5.99\end{array}$

$\begin{array}{lll}.21 & .31 & 1.24\end{array}$

$\begin{array}{lll}-.13 & .48 & .88\end{array}$

$\begin{array}{lll}-.13 & .48 & .88 \\ -.33 & .61 & .72\end{array}$

.

$\begin{array}{rrrl}-.06 & .45 & .94 & \mathrm{~ns} \\ .91 & .47 & 2.48 & \wedge \\ -.30 & .76 & .74 & \mathrm{~ns} \\ 1.71 & 1.49 & 5.54 & \mathrm{~ns} \\ & & & \\ -.02 & .09 & .98 & \mathrm{~ns} \\ .36 & .25 & 1.43 & \mathrm{~ns} \\ & & & \\ -2.98 & 2.16 & .05 & \mathrm{~ns}\end{array}$


women. The odds of trying to conceive compared to being okay decline with each child.

More characteristics distinguish those trying not to conceive from those who are okay either way. In addition to fertility intentions, ideal number of children and wanting a baby are uniquely associated with lower odds of trying not to get pregnant. Trusting one's ability to get pregnant and self identifying a fertility problem are also associated with trying not to conceive. Only among women with no prior pregnancy is considering career success very important associated with higher odds of trying not to conceive compared to being okay either way. Higher relationship satisfaction is associated with lower odds of trying not to conceive. Consistent with the strong two child norm, parity 1 is not associated with pregnancy intentions, but parity 2 and $3+$ are. As parity increases, women are more likely to say that they are trying not to get pregnant. Compared to white women, Hispanic, Black, and Asian women have lower odds of trying not to get pregnant than being okay either way. Higher economic hardship is associated with higher odds of trying not to conceive (compared to being okay either way).

\section{Limitations and Conclusions}

As with many studies, our project suffers from limitations. First, we have retrospective reports of first pregnancies. Therefore we cannot be sure of the accuracy of

Table 3 (continued).

\begin{tabular}{|c|c|c|c|c|c|c|c|c|}
\hline \multirow[b]{2}{*}{ Trying not to v. Okay } & \multicolumn{4}{|c|}{$\begin{array}{c}(1) \\
\text { Pregnancy Intention } \\
\text { Includes all cases that are } \\
\text { sexually active }\end{array}$} & \multicolumn{4}{|c|}{$\begin{array}{c}(2) \\
\text { Pregnancy Intention } \\
\text { Includes never pregnant }\end{array}$} \\
\hline & Coef. & SE & OR & $P$ & Coef. & SE & OR & $P$ \\
\hline \multicolumn{9}{|l|}{ Attitudes } \\
\hline Ideal Number of Children & -.76 & .22 & .47 & $* *$ & -.02 & .42 & .98 & \\
\hline Importance of Motherhood & .01 & .15 & 1.01 & & -.03 & .24 & .97 & \\
\hline Religiosity & -.02 & .08 & .98 & & .18 & .15 & 1.20 & \\
\hline Trust will get pregnant & -.34 & .10 & .71 & $* *$ & -.46 & .19 & .63 & * \\
\hline Career very important & .09 & .13 & 1.09 & & .60 & .28 & 1.82 & * \\
\hline Leisure very important & -.14 & .13 & .87 & & .23 & .28 & 1.26 & \\
\hline Most friends/family have kids & -.28 & .18 & .76 & & -.42 & .29 & .66 & \\
\hline \multicolumn{9}{|c|}{ Life course } \\
\hline Age & .03 & .16 & 1.03 & & -.07 & .26 & .94 & \\
\hline Married & .15 & .57 & 1.17 & & -.74 & .99 & .48 & \\
\hline Cohabiting & -.50 & .71 & .61 & & .28 & 1.14 & 1.32 & \\
\hline Relationship satisfaction & -.42 & .13 & .66 & $* *$ & -.07 & .27 & .93 & \\
\hline Employed Full Time & .04 & .16 & 1.05 & & -.57 & .38 & .56 & \\
\hline Employed Part Time & .02 & .21 & 1.02 & & -.22 & .58 & .80 & \\
\hline Parity 1 & .09 & .20 & 1.09 & & & & & \\
\hline Parity 2 & .52 & .24 & 1.69 & * & & & & \\
\hline Parity 3 or higher & .74 & .26 & 2.10 & $* *$ & & & & \\
\hline \multicolumn{9}{|l|}{ Ethnicity or Race } \\
\hline Constant & 3.70 & .91 & 40.53 & $* * *$ & 3.90 & 1.63 & 49.58 & * \\
\hline Nagelkerke $\mathrm{R}^{2}$ & .34 & & & & .51 & & & \\
\hline
\end{tabular}

Note: Okay either way is the base category.

$\wedge p<.01 ;{ }^{*} p<.05 ;{ }^{* *} p<.01 ;{ }^{* * *} p<.001$ 
these responses. Additionally, we do not have information about women at the time of their first pregnancy for characteristics that can change, such as attitudes. We attempted to compensate for these limitations by separately analyzing women who are currently sexually active and have not yet had a pregnancy compared to all currently sexually active women. Additionally, we cannot assess nuances in the degree of trying to, trying not to, or "okay either way" attitudes because women were asked to place themselves in one of these categories.

Additionally, survey research is limited for generating deeper understanding of women's experiences of pregnancy intentions. The phrase "okay either way," however, emerged from face-to-face conversations with women during the survey development phrase that were designed to understand how women talk about and think about pregnancy intentions. Therefore, we hope that this new category helps to take advantage of the strengths of survey research (generalizability and representativeness), and will complement the strengths of in-depth studies of women's experiences.

We have not captured many additional factors that are potentially associated with pregnancy intentionsinformation about sexual relations throughout the life cycle, awareness of one's own and partner's desire, or not, for children; information on who is involved in decision-making beyond the individual, gender preferences for children; the impact of work, migration, and social support on decision-making - that can influence pregnancy intentions. Because the NSFB survey was primarily designed to study infertility, it is lacking these measures that would enrich our analysis. Space limitations necessitate a narrow focus for this first exploration of the benefits of including "okay either way" as a category of pregnancy intention.

Despite limitations, we offer several contributions. These analyses demonstrate that many women's pregnancies do not fit into the "intended/unintended" or "trying/trying not to" categories often used to describe women's pregnancy intentions. Our findings address a concern among scholars of pregnancy intentions who have been frustrated with the dichotomous survey options in the past (e.g., 2, 5, 11, 19-23). Nearly a quarter of women say that they are "okay either way" about getting pregnant. The three groups of women analyzed here display distinct profiles with regard to parity, age, race, trust in getting pregnant, and importance of motherhood. For many of these variables, women who were okay either way occupy middle ground between women who were trying to become pregnant and women who were trying not to become pregnant. We also found instances, however, where women who were okay either way resembled women who were trying to become pregnant in contrast to those who were trying not to become pregnant. Women who were okay either way resembled those trying not to become pregnant more than they resembled those trying to become pregnant on several characteristics. In some cases our data are consistent with the idea that being okay either way is between trying to and trying not to, as if on a continuum (10). There are a few variables in which women in the "okay" category do not differ from women who are trying to or not trying to conceive, but for most variables the "okay" group is unique.

Pregnancy intentions can change with women's situations and experiences. Future research should examine the individual and social characteristics associated with changes in intentions. For example, women who experience fertility barriers may convert to a more concerted trying approach to pregnancy, or could decide to accept what happens. Understanding how pregnancy intentions change with changes in partners, jobs, aging, and historical events is important for assessing women's need for pregnancy education and health care. Expanding the categories of pregnancy intentions complicates research on fertility, but we suggest that the added complexity is worth the increase in more accurately capturing women's experiences. Paying greater attention to women who say that they are "okay either way" may help caregivers in efforts to reduce ambivalence and help guide women toward making pregnancy decisions, enabling those who become pregnant to better prepare for pregnancy.

\section{Acknowledgments}

The data for this paper was supported by NICHD grant \#1R01HD044144 01A1. We are grateful for the collaboration with our research team: Mary Casey Jacob, Naomi Lacy, David R. Johnson, Laurie Scheuble, Katie Johnson, and Lynn White We are also grateful for the editorial assistance of Jessica Iwachiw, and fruitful suggestions from the anonymous reviewers of the Maternal and Child Health Journal. An earlier version of this paper was presented at the Midwest Sociological Association meeting in Des Moines, IA, April 2, 2009.

\section{References}

1. Brown, S. S, \& Eisenberg, L. (Eds.). (1995). The best intentions: Unintended pregnancy and the well-being of children and families. Washington, DC: National Academy Press.

2. Morgan, S. P. (1982). Parity-specific fertility intentions and uncertainty: The United States, 1970 to 1976. Demography, 19, 315-334.

3. Greil, A. L., \& McQuillan, J. (forthcoming). Trying times: medicalization, intent, and ambiguity in the definition of infertility. Medical Anthropology Quarterly.

4. Santelli, J. S., Rochat, R., Hatfield-Timajchy, K., Gilbert, B. C., Curtis, K., Cabral, R., Hirsch, J. S., Schieve, L., et al. (2003). The measurement and meaning of unintended pregnancy. Perspectives on Sexual and Reproductive Health, 34, 206-211. 
5. Santelli, J. S., Lindberg, L. D., Orr, M. G., Finer, L. B., \& I. Speizer, I. (2009). Toward a multidimensional measure of pregnancy intentions: Evidence from the United States. Studies in Family Planning, 40, 87-100.

6. White, L., \& McQuillan, J. (1999). No longer intending: The relationship between relinquished fertility intentions and distress. Journal of Marriage and Family, 68, 478-490.

7. Williams, L., Abma, J., \& Piccinino, L. J. (1999). The correspondence between intention to avoid childbearing and subsequent fertility: A prospective analysis. Family Planning Perspectives, 31, 220-227.

8. Zabin, L. S., Huggins, G. R., Emerson, M. R., \& Cullins, V. E. (2000). Partner effects on a woman's intention to conceive: "Not with this partner." Family Planning Perspectives, 32, 39-45.

9. D'Angelo, D. V., Gilbert, B. C., Rochat, R. W., Santelli, J. S., \& Herold, J. M. (2004). Differences between mistimed and unwanted pregnancies among women who have live births." Perspectives on Sexual and Reproductive Health, 36, 192-197.

10. Finer, L. B., \& Henshaw, S. K. (2006). Disparities in rates of unintended pregnancy in the United States, 1994 and 2001. Perspectives on Sexual and Reproductive Health 38, 90-96.

11. Barrett, G., \& Wellings, K. (2002). What is a "planned" pregnancy? Empirical data from a British study. Social Science and Medicine, 55, 545-557.

12. Bachrach, C. A., \& Newcomer, S. (1999). Intended pregnancies and unintended pregnancies: distinct categories or opposite ends of a continuum? Family Planning Perspectives, 31, 251-252.

13. Schoen, R., Astone, N. M., Kim, Y. J., Nathanson, C. A., \& Fields, J. M. (1999). Do fertility intentions affect fertility behavior? Journal of Marriage and the Family, 61, 790-799.

14. Kaufman, G. (2000). Do gender role attitudes matter? Family formation and dissolution among traditional and egalitarian men and women." Journal of Family Issues, 21, 128-144.

15. Stanford, J. B., Hobbs, R., Jameson, P., DeWitt, M. J., \& Fischer, R. C. (2000). Defining dimensions of pregnancy intendedness. Maternal and Child Health, 4, 183-189.

16. Stewart, S. D. (2002). The effect of stepchildren on childbearing intentions and births. Demography, 39, 181-197.

17. Hayford, S. R., \& Morgan, S. P. (2008). Religiosity and fertility in the United States: The role of fertility intentions. Social Forces 86, 1163-1188.
18. Sassler, S., Miller, A., \& Favinger, S. M. (2009). "Planned" parenthood? Fertility intentions and experiences among cohabiting couples. Journal of Family Issues, 30, 206-232.

19. Finlay, A. (1996). Teenage pregnancy, romantic love, and social science: An uneasy relationship. In V. James \& J. Gabe (Eds.), Health and Sociology of the Emotions (pp. 79- 96). Oxford: Blackwell.

20. Luker, K. C. (1999). A reminder that human behavior frequently refuses to conform to models created by researchers. Family Planning Perspectives, 31, 248-249.

21. Sable, M. R., \& Libbus, M. K. (2000.) Pregnancy intention and pregnancy happiness: Are they different? Maternal and Child Health, 6, 181-187.

22. Speizer, I. S., Santelli, J. S., Afable-Munsuz, A., \& C. Kendall, C. (2004). Measuring factors underlying intendedness of women's first and later pregnancies. Perspectives on Sexual and Reproductive Health, 26, 198-205.

23. Hagewen, K. J., \& Morgan, S. P. (2005). Intended and ideal family size in the United States, 1970-2002. Population and Development Review, 31, 507-527.

24. Lifflander, A., Gaydos, L. M. D., \& Rowland Hogue, C. J. (2007). Circumstances of pregnancy: Low income women in Georgia describe the difference between planned and unplanned pregnancies. Maternal and Child Health, 11, 81-89.

25. Rijken, A. J. (2009). Happy families, high fertility? Childbearing choices in the context of family and partner relationships. Doctoral dissertation, Utrecht University (ICS Dissertation Series no. 154), Utrecht, The Netherlands.

26. Kost, K., Singh, S., Vaughan, B., Trussell, J., \& Bankole, A. (2008). Estimates of contraceptive failure from the $2002 \mathrm{Na}-$ tional Survey of Family Growth." Contraception, 77, 10-21.

27. Zabin, L. S. (1999). Ambivalent feelings about parenthood may lead to inconsistent contraceptive use and pregnancy. Family Planning Perspectives, 31, 250-251.

28. Johnson, D. R., \& White, L. K. National Survey of Fertility Barriers [Data file]. Retrieved from the Pennsylvania State University Population Research Institute Web site http:// pennstate $\backslash$ sodapop $\backslash$ nsfb. n.d.

29. McCarty, C., House, M., Harman, J., \& Richards, S. (2006). Effort in phone survey response rates: The effects of vendor and client-controlled factors. Field Methods, 18, 72-188. 